\title{
Pd/Ni-Catalyzed Germa-Suzuki Coupling via Dual Ge-F Bond Activation
}

Hajime Kameo, ${ }^{* a}$ Akihiro Mushiake, ${ }^{a}$ Tomohito Isasa, ${ }^{a}$ Hiroyuki Matsuzaka ${ }^{a}$ and Didier Bourissou $* \mathrm{~b}$

\author{
Department of Chemistry, Graduate School of Science, Osaka Prefecture University, Osaka 599-8531, Japan. E-mail: h.kameo@c.s.osakafu-u.ac.jp \\ Laboratoire Hétérochimie Fondamentale et Appliquée, Université Paul Sabatier/ CNRS UMR 5069, 118 Route de Narbonne, 31062 Toulouse Cedex \\ 09, France.E-mail: dbouriss@chimie.ups-tlse.fr \\ † Dedicated to Dr. Jean Escudié.
}

\begin{abstract}
:
$\mathrm{Pd} / \mathrm{Ni} \rightarrow \mathrm{Ge}-\mathrm{F}$ interactions supported by phosphine-chelation were found to trigger dual activation of $\mathrm{Ge}-\mathrm{F}$ bonds under mild conditions. This makes fluoro germanes suitable partners for catalytic $\mathrm{Ge}-\mathrm{C}$ cross-coupling and enables Germa-Suzuki reactions to be achieved for the first time.
\end{abstract}


Organo germanium compounds are powerful transfer reagents for catalytic cross-coupling reactions. ${ }^{1}$ They also find applications in materials science. ${ }^{2}$ The formation of $\mathrm{C}-\mathrm{Ge}$ bonds is thus of importance and the advent of new synthetic methodologies is highly desirable to widen the scope of usable substrates and accessible products.

Hydrogermylation involving transition metal or radical-mediated pathways is efficient and useful, but intrinsically limited to the synthesis of alkyl- and alkenyl-substituted germanes. ${ }^{3-5}$ The most general way to forge $\mathrm{Ge}-\mathrm{C}$ bonds is probably the ionic coupling of organometallic compounds with germanium halides or alkoxides (reactions between Ge-based nucleophiles and organic electrophiles are also known but less common). ${ }^{6}$ Transition metal catalysis is extremely powerful and broadly used for $\mathrm{C}-\mathrm{C}$ and $\mathrm{C}-\mathrm{X}$ bond formation. It has certainly great potential for $\mathrm{Ge}-\mathrm{C}$ crosscoupling as well, although the field is still in its infancy with only very few recent reports (Figure 1). Xiao and co-workers reported in $2018 \mathrm{Pd}$-catalyzed couplings of a hydrogermatrane with aryl halides and pseudo-halides. ${ }^{1 \mathrm{~d}}$ The approach was then extended by Schoenebeck et al. to the coupling of $\mathrm{Et}_{3} \mathrm{GeH}$ with aryl thiathrenium salts using $\mathrm{Pd}(\mathrm{I})$ dimers as catalysts. ${ }^{1 \mathrm{k}}$ In addition, Oestreich et al. significantly advanced the use of Ge-based nucleophiles in $\mathrm{Ge}-\mathrm{C}\left(\mathrm{sp}^{3}\right)$ cross-coupling and described in 2019 a very elegant Germa-Negishi type reaction. ${ }^{7}$ We envisioned a radically different approach, namely cross-coupling with a Ge-based electrophile. ${ }^{8}$ Our recent discovery of facile Si-F bond activation thanks to transition metal / Lewis acid cooperation opened the way to catalytic SilaNegishi coupling from fluoro-silanes. ${ }^{9}$ Here we demonstrate that this concept can be extended to Germanium chemistry. The combination of Pd or Ni with a Lewis acid enables dual activation of $\mathrm{Ge}-$ $\mathrm{F}$ bonds. ${ }^{10}$ Accordingly, fluoro germanes were found to undergo $\mathrm{Ge}-\mathrm{C}$ cross-couplings with organo boron reagents, providing the first examples of Germa-Suzuki reactions.

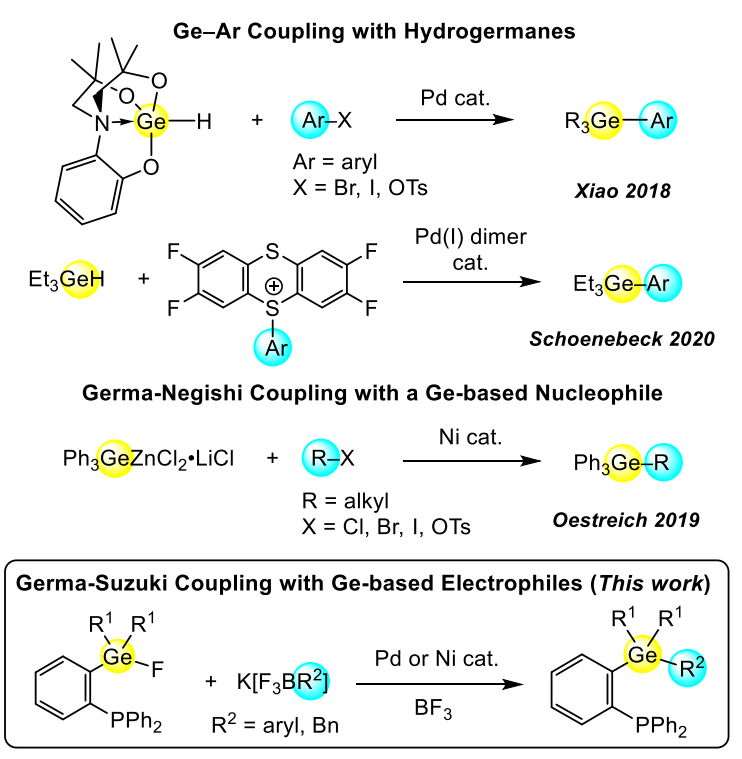

Figure 1 Transition metal-catalyzed Ge-C cross-couplings.

Fluoro germanes have been shown in previous studies to engage in $M \rightarrow G e-F$ interactions $(M=C u$, $\mathrm{Ag}, \mathrm{Au}$ ) when chelated by phosphines, and to be stronger ?-acceptor ligands than fluoro silanes. ${ }^{11}$ We thus envisioned to take advantage of P-chelation to trigger $\mathrm{Ge}-\mathrm{F}$ activation and cross-coupling. Given the availability and efficiency of boron reagents as nucleophiles, we sought to develop a hitherto unknown Germa-Suzuki reaction. The fluoro germane $\left\{\left(0-\mathrm{Ph}_{2} \mathrm{P}\right) \mathrm{C}_{6} \mathrm{H}_{4}\right\} \mathrm{GePh}_{2} \mathrm{~F} \mathbf{1}^{\mathrm{Ge}}$ was used as substrate and several aryl boron derivatives were tested. Gratifyingly, quantitative $\mathrm{Ge}-\mathrm{Ph}$ coupling was observed using $\mathrm{BPh}_{3}$ with either $\mathrm{Pd}_{2}(\mathrm{dba})_{3}$ or $\mathrm{Ni}(\mathrm{COD})_{2}$ (Table 1 , entries 1 and 2). The 
nature of the borane is critical: no reaction occurred when the less Lewis acidic borane PhBpin or the very Lewis acidic borane $B\left(C_{6} F_{5}\right)_{3}$ were used (entries 3 and 4 ). The formation of $F_{2} B P h, B F_{3}$, and $\mathrm{BF}_{4}{ }^{-}$by-products from $\mathrm{BPh}_{3}$ (as apparent from ${ }^{19} \mathrm{~F}\left\{{ }^{1} \mathrm{H}\right\} \mathrm{NMR}$ spectroscopy, Figure $\mathrm{S} 1$ ) ${ }^{\ddagger}$ suggests that the borane acts both as $\mathrm{Ph}$ source (arylating reagent) and a $\mathrm{F}$ acceptor (Lewis acid) in this transformation. Of note, the corresponding fluoro silane $\left\{\left(\mathrm{o}-\mathrm{Ph}_{2} \mathrm{P}\right) \mathrm{C}_{6} \mathrm{H}_{4}\right\} \mathrm{SiPh}_{2} \mathrm{~F}\left(\mathbf{1}^{\mathrm{Si}}\right)$ remains inert under similar conditions (entry 5 ), indicating that only the $\mathrm{Ge}-\mathrm{F}$ bond can be activated and crosscoupled this way, probably due to stronger $\mathrm{M} \rightarrow \mathrm{Ge}-\mathrm{F}$ interaction. Phenylation of the diphosphine fluoro germane $\left\{\left(0-\mathrm{Ph}_{2} \mathrm{P}\right) \mathrm{C}_{6} \mathrm{H}_{4}\right\}_{2} \mathrm{GePhF}(3)^{10}$ was also possible with both $\mathrm{Pd}$ and $\mathrm{Ni}$ catalysts using $\mathrm{BPh}_{3}$ (entries 6 and 7). Again, no cross-coupling was observed using PhBpin or $\mathrm{B}\left(\mathrm{C}_{6} \mathrm{~F}_{5}\right)_{3}$ (entries 8 and 9). Varying the aryl source and Lewis acid with $\mathbf{1}^{\text {Ge }}$ as substrate, we then realized that the reaction can be most conveniently achieved using the trifluoroborate salt $\mathrm{K}\left(\mathrm{F}_{3} \mathrm{BPh}\right)$ along with $\mathrm{BF}_{3}$. With this combination, modest results were obtained in THF (probably due to inhibition of the Lewis acidassisted Ge-F activation). However, shifting to 2-methyl tetrahydrofuran (2-MTHF) as solvent drastically improved the catalytic activity and the desired Ge-Ph coupling product $\mathbf{2}$ was obtained in excellent yields (entries 10 and 11 ). Note that $\mathrm{K}\left[\mathrm{F}_{3} \mathrm{BPh}\right]$ alone is unproductive, the concomitant use of $\mathrm{BF}_{3}$ is essential for the catalysis to proceed (entry 12). Phosphine chelation also plays an important role, no reaction being observed under the same conditions from $\mathrm{FGePh}_{3}$.

Table 1 Germa-Suzuki cross-coupling reactions of the fluoro germanes $\mathbf{1}^{\text {Ge }}$ and 3.

\begin{tabular}{|c|c|c|c|c|}
\hline $\begin{array}{l}1^{G e} \\
3^{G}\end{array}$ & $\begin{aligned} R^{1} \\
R^{1}= \\
(0-P\end{aligned}$ & $\begin{array}{l}\mathrm{R}^{2}=\mathrm{Ph} \\
\left.\mathrm{h}_{2} \mathrm{P}\right) \mathrm{C}_{6} \mathrm{H}_{4}, \mathrm{R}^{2}=\mathrm{Ph}\end{array}$ & $\begin{array}{l}2 \\
4\end{array}$ & \\
\hline Entry & Substrate & Catalyst & Ar source / L. A. & Yield(\%) ${ }^{a}$ \\
\hline 1 & $1^{\mathrm{Ge}}$ & $\mathrm{Pd}_{2}(\mathrm{dba})_{3}$ & $\mathrm{BPh}_{3}{ }^{b}$ & 99 \\
\hline 2 & $1^{\mathrm{Ge}}$ & $\mathrm{Ni}(\mathrm{COD})_{2}$ & $\mathrm{BPh}_{3}{ }^{b}$ & 99 \\
\hline 3 & $1^{\mathrm{Ge}}$ & $\mathrm{Pd}_{2}(\mathrm{dba})_{3}$ & PhBpin $^{c}$ & 0 \\
\hline 4 & $1^{\mathrm{Ge}}$ & $\mathrm{Pd}_{2}(\mathrm{dba})_{3}$ & $\mathrm{~B}\left(\mathrm{C}_{6} \mathrm{~F}_{5}\right)_{3}^{b}$ & 0 \\
\hline 5 & $1^{\mathrm{Si}}$ & $\mathrm{Pd}_{2}(\mathrm{dba})_{3}$ & $\mathrm{BPh}_{3}{ }^{b}$ & 0 \\
\hline $6^{d}$ & 3 & $\mathrm{Pd}_{2}(\mathrm{dba})_{3}$ & $\mathrm{BPh}_{3}{ }^{b}$ & 79 \\
\hline $7^{d}$ & 3 & $\mathrm{Ni}(\mathrm{COD})_{2}$ & $\mathrm{BPh}_{3}{ }^{b}$ & 47 \\
\hline $8^{d}$ & 3 & $\mathrm{Pd}_{2}(\mathrm{dba})_{3}$ & $\mathrm{PhBpin}^{c}$ & 0 \\
\hline $9^{d}$ & 3 & $\mathrm{Pd}_{2}(\mathrm{dba})_{3}$ & $\mathrm{~B}\left(\mathrm{C}_{6} \mathrm{~F}_{5}\right)_{3}^{b}$ & 0 \\
\hline 10 & $1^{\mathrm{Ge}}$ & $\mathrm{Pd}_{2}(\mathrm{dba})_{3}$ & $\mathrm{~K}\left(\mathrm{~F}_{3} \mathrm{BPh}\right) / \mathrm{BF}_{3} \cdot \mathrm{OEt}_{2}$ & $49(96)^{e}$ \\
\hline 11 & $1^{\mathrm{Ge}}$ & $\mathrm{Ni}(\mathrm{COD})_{2}$ & $\mathrm{~K}\left(\mathrm{~F}_{3} \mathrm{BPh}\right) / \mathrm{BF}_{3} \cdot \mathrm{OEt}_{2}$ & $8(99)^{e, f}$ \\
\hline 12 & $1^{\mathrm{Ge}}$ & $\mathrm{Ni}(\mathrm{COD})_{2}$ & $\mathrm{~K}\left(\mathrm{~F}_{3} \mathrm{BPh}\right) /$ none & $0(0)^{e}$ \\
\hline 13 & 3 & $7^{\mathrm{Ge}}$ & $\mathrm{BPh}_{3}{ }^{b}$ & 86 \\
\hline 14 & 3 & $8 c^{G e}$ & $\mathrm{BPh}_{3}{ }^{b}$ & 89 \\
\hline
\end{tabular}


${ }^{a}$ Determined by ${ }^{31} \mathrm{P}$ NMR. ${ }^{b} 1.5$ eq. ${ }^{c} 5$ eq. ${ }^{d} 10$ mol\% catalyst, Mesitylene, $160{ }^{\circ} \mathrm{C}, 20$ h. ${ }^{e} 2-\mathrm{MTHF}$. flsolated yield: $68 \%$.

The substrate scope was then investigated employing the following optimal conditions: $\mathrm{Ni}(\mathrm{COD})_{2}$, $\mathrm{K}\left(\mathrm{F}_{3} \mathrm{BR}\right)$ and $\mathrm{BF}_{3}$ in 2-MTHF (Table 2). Phenylation of the fluoro germane $\left\{\left(0-\mathrm{Ph}_{2} \mathrm{P}\right) \mathrm{C}_{6} \mathrm{H}_{4}\right\} \mathrm{GeMe}_{2} \mathrm{~F}(5)$ featuring methyl substituents at Ge worked nicely. The reaction proceeded well with a variety of trifluoro(aryl)borates featuring electron-donating $\left(\mathrm{OMe}_{2} \mathrm{NMe}_{2}\right)$ as well electron-withdrawing (CN, $\left.\mathrm{CF}_{3}, \mathrm{~F}, \mathrm{Cl}\right)$ groups. $\mathrm{Ge}-\mathrm{C}\left(\mathrm{sp}^{3}\right)$ coupling worked with $\mathrm{K}\left(\mathrm{F}_{3} \mathrm{BBn}\right)$ but not with $n$-alkyl substrates prone to ? - $\mathrm{H}$ elimination such as $\mathrm{K}\left[\mathrm{EtBF}_{3}\right]$ and $\mathrm{K}\left[n-\mathrm{BuBF}_{3}\right]^{. \neq}$

Table 2 Scope of borate reagents for the Germa-Suzuki Coupling of fluoro germane $\mathbf{5}^{a}$
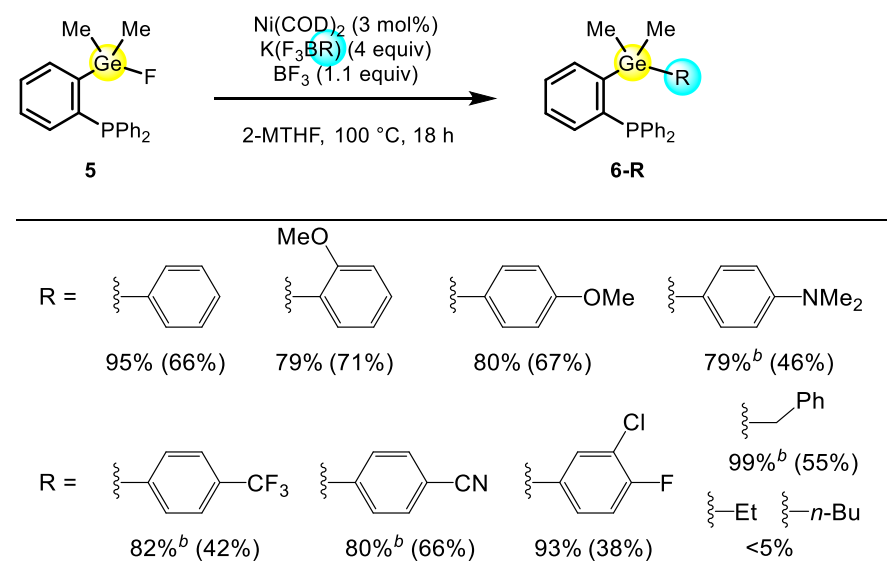

${ }^{a}$ Spectroscopic yields, as determined by ${ }^{31} \mathrm{P}$ NMR spectroscopy (isolated yields are given in parentheses). ${ }^{b} 120^{\circ} \mathrm{C}$.

Competitive experiments ${ }^{12}$ were then carried out with a $1: 1$ mixture of 5 and $\mathbf{5}^{\mathrm{Cl}}$ in order to compare the reactivity of fluoro and chloro germanes towards $\mathrm{Ge}-\mathrm{C}$ coupling (Figure 2). When $\mathrm{ZnPh}_{2}$ was used as arylating reagent, only the chloro germane reacted to give 6-Ph. An opposite chemoselectivity was achieved with $\mathrm{Ni}(\mathrm{COD})_{2}, \mathrm{~K}\left(\mathrm{~F}_{3} \mathrm{BR}\right)$ and $\mathrm{BF}_{3}$. Only the fluoro germane $\mathbf{5}$ was found to undergo cross-coupling under these conditions, $5^{\mathrm{Cl}}$ remained unchanged.

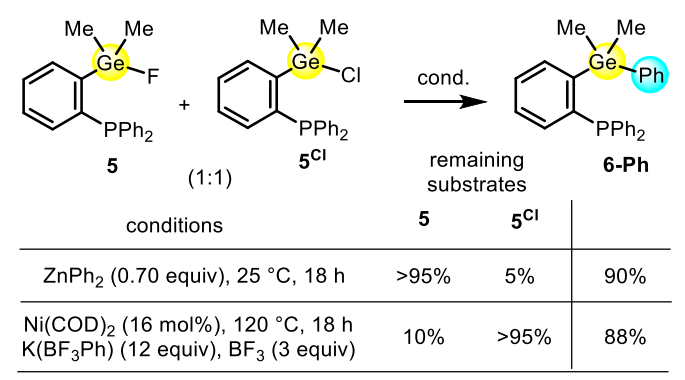

Figure 2 Competitive phenylations of $\mathrm{Ge}-\mathrm{Cl}$ and $\mathrm{Ge}-\mathrm{F}$ bonds. 
By analogy with the related Sila-Negishi coupling, ${ }^{9}$ we propose the catalytic cycle shown in Fig. 3 to account for the Germa-Suzuki coupling. To support the feasibility and relevance of this pathway, the formation, structure and reactivity of $\mathrm{Pd}$ complexes deriving from the diphosphine fluoro germane 3 were investigated. Complex $7^{\mathrm{Ge}}$ was first synthesized by ligand exchange (step $i$ ). In contrast with the related diphosphine fluoro silane complex, ${ }^{9} 7^{\mathrm{Ge}}$ proved unstable in the absence of excess $\mathrm{PPh}_{3}$. Notwithstanding, crystals of $7^{\mathrm{Ge}}$ suitable for X-ray diffraction analysis could be obtained (Figure 3 (a)). The Pd center is in tetrahedral environment, with the fluoro germane moiety coordinated via $\mathrm{Ge}\left(\mathrm{Pd}{ }^{\cdots} \mathrm{Ge} 2.7518(5) \AA\right)$ and $\mathrm{C}_{\text {ipso }}\left(\mathrm{Pd}^{\cdots}{ }^{\cdots} \mathrm{C} 2.638(3) \AA\right)$ in addition to the three P atoms. The germane moiety behaves as a Z-type ligand in complex $\mathbf{7}^{\mathrm{Ge}} \cdot{ }^{11,13,14}$ The Ge-Pd distance is only slightly longer than the sum of covalent radii $(2.53 \AA),{ }^{15}$ and despite the larger radius of Ge compared to Si (1.20 vs $1.11 \AA$ A) ${ }^{15}$ it is significantly shorter than the Pd ${ }^{\cdots}$ Si distance in the Si analogue of $7^{\mathrm{Ge}}(2.9770$ (8) $\AA$ in $\left.\left[\left\{\left(o-\mathrm{Ph}_{2} \mathrm{P}\right) \mathrm{C}_{6} \mathrm{H}_{4}\right\}_{2} \mathrm{SiPhF}\right]\left[\mathrm{Pd}\left(\mathrm{PPh}_{3}\right)\right]\left(7^{\mathrm{Si}}\right)\right) \cdot{ }^{9}$ Additional signs for $\mathrm{Pd} \rightarrow \mathrm{Ge}-\mathrm{F}$ interaction in complex $7^{\mathrm{Ge}}$ are the elongation of the Ge-F bond [1.8246(19) $\AA$ vs $1.762(2) \AA$ in $\left.\left\{\left(0-\mathrm{Ph}_{2} \mathrm{P}\right) \mathrm{C}_{6} \mathrm{H}_{4}\right\}_{3} \mathrm{GeF}^{16}\right]$ and the trigonal pyramidal geometry around $\mathrm{Ge}$ the sum of $\mathrm{C}-\mathrm{Ge}-\mathrm{C}$ angles $=358.81(22)^{\circ}, \mathrm{Pd} \cdots \mathrm{Ge}-\mathrm{F}$ bond angle $=157.94(6)^{\circ} \mathrm{J}$. Consistently, NBO analysis (DFT) shows the presence of a substantial donoracceptor $\mathrm{d}(\mathrm{Pd}) \rightarrow \mathrm{Q}^{*}(\mathrm{Ge}-\mathrm{F})$ interaction $(15.8 \mathrm{kcal} / \mathrm{mol})$ at the second-order perturbation level.

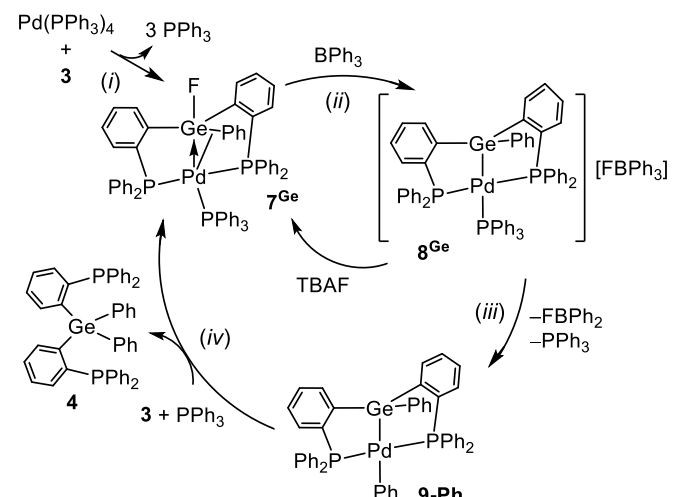

(a)

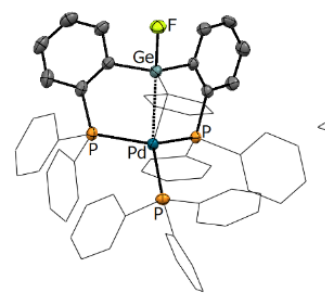

(b)

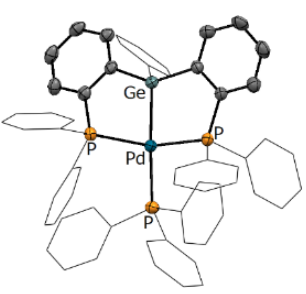

(c)

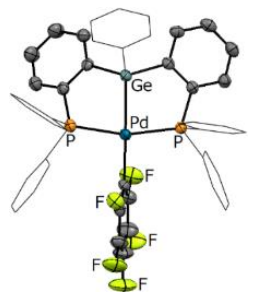

Figure 3 Catalytic cycle proposed to account for the Germa-Suzuki coupling. Molecular structures of the isolated catalytic intermediates $\mathbf{7}^{\mathbf{G e}}(a), \mathbf{8}^{\mathbf{G e}}(b)$ and $\mathbf{9}-\mathbf{C}_{6} \mathbf{F}_{5}(c)$ complexes (the Ph substituents at phosphorus and germanium are simplified, the hydrogen atoms and counter-anion for $\mathbf{8}^{\mathrm{Ge}}$ are omitted for clarity).

Activation of the Ge-F bond at Pd was then studied (step ii). Upon treatment with boranes such as $\mathrm{BF}_{3}, \mathrm{BPh}_{3}$ and $\mathrm{B}\left(\mathrm{C}_{6} \mathrm{~F}_{5}\right)$, complex $7^{\mathrm{Ge}}$ readily afforded the cationic germyl complex $[\{(0-$ $\left.\left.\left.\left.\mathrm{Ph}_{2} \mathrm{P}\right) \mathrm{C}_{6} \mathrm{H}_{4}\right\}_{2} \mathrm{PhGe}\left\{\mathrm{Pd}\left(\mathrm{PPh}_{3}\right)\right\}\right]\left[\mathrm{FBR}_{3}\right]\left(\mathbf{8}^{\mathrm{Ge}}-\mathrm{FBR}_{3}\right)\left(\mathrm{R}=\mathrm{F}, \mathrm{Ph}, \mathrm{C}_{6} \mathrm{~F}_{5}\right)\right) .{ }^{17}$ The molecular structure of $\mathbf{8}^{\mathrm{Ge}}$ was confirmed by $\mathrm{X}$-ray diffraction analysis after counter-anion exchange (complex $\mathbf{8}^{\mathrm{Ge}}-\mathbf{B P h}_{\mathbf{4}}$, Figure 3 (b)). As expected, the Pd-Ge distance [2.4051(3) $\AA$ ] is much shorter than in $7^{\mathrm{Ge}}$ and only marginally exceeds the sum of covalent radii. With a less Lewis acidic borane such as PhBpin, the germane $7^{\mathrm{Ge}}$ 
remains intact, in line with the absence of catalytic activity observed when using PhBpin as coupling partner (entries 3 and 8, Table 1). Note that the facile Ge-F bond cleavage from $7^{\mathrm{Ge}}$ in the presence of $\mathrm{BPh}_{3}$ markedly contrasts with the inertness of the $\mathrm{Si}-\mathrm{F}$ bond of $\mathbf{7}^{\mathrm{Si}}$ under similar conditions. The fluoro silane complex remains unchanged when treated with $\mathrm{BPh}_{3}$ even upon heating at $160^{\circ} \mathrm{C}$ (see below for a tentative explanation based on DFT calculations). Interestingly, the Ge-F bond activation is reversible. Indeed, the addition of tetrabutylammonium fluoride (TBAF) to $\mathbf{8}^{\mathbf{G e}} \mathbf{- B P h}$ at room temperature immediately and quantitatively regenerates the fluoro germane complex $7^{\mathrm{Ge}}$. The interconversion of Z-type and X-type ligands has recently attracted much interest and clear-cut examples have been authenticated with $\mathrm{B},{ }^{18} \mathrm{Si}^{9}{ }^{9} \mathrm{Sb}^{19}$ and $\mathrm{Sn} .{ }^{20}$ To our knowledge, the back and forth between $7^{\mathrm{Ge}}$ and $\mathbf{8}^{\mathrm{Ge}}$ represents a first case with Z-germane and X-germyl moieties.

To gain further insight into the Ge-F bond activation from the fluoro germane $\mathbf{7}^{\mathrm{Ge}}$ to the germyl $\mathbf{8}^{\mathrm{Ge}}$ species, DFT calculations were performed with $\mathrm{BPh}_{3}$ as Lewis acid (Figure 4). For comparison, similar studies were carried out on $\mathrm{Si}-\mathrm{F}$ bond activation. The interaction of $7^{\mathrm{Ge}}$ with $\mathrm{BPh}_{3}$ is slightly exergonic ( $\Delta G=-0.4 \mathrm{kcal} / \mathrm{mol}$ ). It induces further elongation of the $\mathrm{Ge}-\mathrm{F}$ bond (from 1.866 to 1.894 $\AA$ ) while the $\mathrm{Pd}-\mathrm{Ge}$ bond slightly shortens (from 2.777 to $2.741 \AA$ ). The subsequent bond cleavage is exergonic $(\Delta \mathrm{G}=-6.3 \mathrm{kcal} / \mathrm{mol})$ and takes place with very small Gibbs activation energies $\left(\Delta \mathrm{G}^{\neq}=\right.$ $2.4 \mathrm{kcal} / \mathrm{mol}$ ) to give the cationic germyl complex $\mathbf{8}^{\mathrm{Ge}}-\mathrm{FBPh}_{3}$. Activation of the $\mathrm{Si}-\mathrm{F}$ bond of $7^{\mathrm{Si}}$ with $\mathrm{BPh}_{3}$ proceeds similarly with a slightly higher but still low activation barrier ( $\left.\Delta \mathrm{G}^{\neq}=5.1 \mathrm{kcal} / \mathrm{mol}\right)$. It is endergonic ( $\Delta G=3.7 \mathrm{kcal} / \mathrm{mol})$, why may explain why no catalytic conversion was observed for this substrate (entry 5 in Table 1). In line with this energy landscape, spontaneous fluoride transfer was observed upon mixing the fluoro germane $\mathbf{7}^{\mathrm{Ge}}$ and silyl $\mathbf{8}^{\mathrm{Si}}-\mathbf{B P h} \mathbf{h}_{\mathbf{4}}$ complexes to give the corresponding germyl $\mathbf{8}^{\mathrm{Ge}}-\mathrm{BPh}_{4}$ and fluoro silane $\mathbf{7}^{\mathrm{Si}}$ species. $^{\ddagger}$

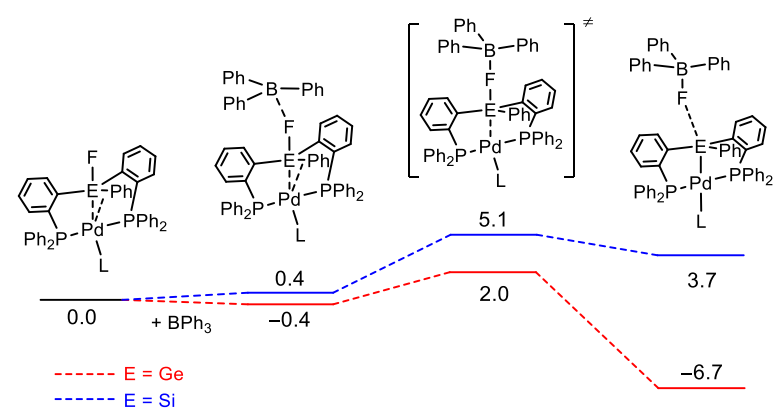

Figure 4 Reaction profiles computed for the Si/Ge-F bond cleavage at Pd assisted by $\mathrm{BPh}_{3}$. Free Gibbs energy changes $(\mathrm{kcal} / \mathrm{mol})$ in THF.

To promote B-to-Pd transmetalation (step iii), $\mathbf{8}^{\mathrm{Ge}}-\mathrm{BPh}_{3} \mathrm{~F}$ was then thermolyzed. The corresponding phenyl complex $\left[\left\{\left(o-\mathrm{Ph}_{2} \mathrm{P}\right) \mathrm{C}_{6} \mathrm{H}_{4}\right\}_{2} \mathrm{PhGe}\right]\{\mathrm{Pd}(\mathrm{Ph})\}($ 9-Ph) was quantitatively obtained after $1 \mathrm{~h}$ at 160 ${ }^{\circ} \mathrm{C}$. Complex 9-Ph proved too unstable to be isolated in pure form, but the analogous pentafluorophenyl species $\left[\left\{\left(0-\mathrm{Ph}_{2} \mathrm{P}\right) \mathrm{C}_{6} \mathrm{H}_{4}\right\}_{2} \mathrm{PhGe}\right]\left\{\mathrm{Pd}\left(\mathrm{C}_{6} \mathrm{~F}_{5}\right)\right\}$ 9- $\mathrm{C}_{6} \mathrm{~F}_{5}$ could be fully characterized (X-ray structure is shown in Figure $3(c)){ }^{\ddagger}$ It is formed when reacting the fluoro germane complex $7^{\mathrm{Ge}}$ with $\mathrm{B}\left(\mathrm{C}_{6} \mathrm{~F}_{5}\right)_{3}$ followed by thermolysis. Transmetalation required prolonged heating ( $83 \%$ conversion after $20 \mathrm{~h}$ at $160{ }^{\circ} \mathrm{C}$ ) and was less clean (44\% yield) in this case. The last step of the catalytic cycle, ie $\mathrm{Ge}-\mathrm{C}$ coupling via reductive elimination (step iv), could also be achieved from 9-Ph. Thermolysis in the presence of $3\left(1 \mathrm{~h}, 160^{\circ} \mathrm{C}\right)$ cleanly and quantitatively afforded the Ge-arylation product 4 
along with the fluoro germane complex $\mathbf{7}^{\mathbf{G e}}$. Note that heating $\mathbf{9}-\mathbf{C}_{6} \mathbf{F}_{\mathbf{5}}$ led to intractable mixtures, with no detectable $\mathrm{Ge}-\mathrm{C}_{6} \mathrm{~F}_{5}$ product, in line with the much lower reactivity of $\mathrm{C}_{6} \mathrm{~F}_{5}$ towards reductive elimination and the absence of catalytic coupling when using $B\left(C_{6} F_{5}\right)_{3}$ as Lewis acid / arylating reagent (Entries 4 and 9 in Table 1 )

The germane $\mathbf{7}^{\mathrm{Ge}}$ and germyl $\mathbf{8}^{\mathrm{Ge}}-\mathbf{B P h}_{\mathbf{4}}$ complexes were engaged in catalytic coupling of the diphosphine fluoro germane 3 with $\mathrm{BPh}_{3}$ (entries 13 and 14 in Table 1). Catalytic activities similar to that achieved with $\mathrm{Pd}_{2}(\mathrm{dba})_{3}$ were obtained, supporting the proposed catalytic cycle. In addition, the cationic $\mathbf{8}^{\mathrm{Ge}}$ and neutral 9-Ph germyl complexes were detected by ${ }^{31} \mathrm{P}$ NMR spectroscopy (in about 8:1 ratio) when monitoring the catalysis. This is consistent with the fact that transmetalation and reductive elimination require more forcing conditions than $\mathrm{Ge}-\mathrm{F}$ bond activation.

In conclusion, Pd/Ni-catalyzed Germa-Suzuki coupling reactions have been carried out for the first time. Fluoro germanes were used as electrophilic coupling partners. The key Ge-F bond cleavage was achieved thanks to phosphine-chelated $\mathrm{Pd} / \mathrm{Ni} \rightarrow \mathrm{Ge}-\mathrm{F}$ interactions. Future work will aim to extend further the application of Z-type coordination to the activation and functionalization of strong ?-bonds.

\section{Acknowledgments}

This work was supported by Grant-in-Aid for Scientific Research (C) (No. 18K05151 and No. 18K05152) of the Ministry of Education, Culture, Sports, Science and Technology (MEXT), Japan. H.K. acknowledges the financial support from the Tokyo Ohka Foundation for the Promotion of Science and Technology. The Centre National de la Recherche Scientifique (CNRS), the Université Paul Sabatier (UPS), and the Agence Nationale de la Recherche (ANR-15-CE07-0003) are acknowledged for financial support of this work.

\section{References}

1 (a) A. C. Spivey, C.-C. Tseng, J. P. Hannah, C. J. G. Gripton, P. de Fraine, N. J. Parr and J. J. Scicinski, Chem. Commun., 2007, 2926-2928; (b) Z.-T. Zhang, J.-P. Pitteloud, L. Cabrera, Y. Liang, M. Toribio and S. Wnuk, Org. Lett., 2010, 12, 816-819; (c) J.-P. Pitteloud, Z.-T. Zhang, Y. Liang, L. Cabrera and S. F. Wnuk, J. Org. Chem., 2010, 75, 8199-8212; (d) H.-J. Song, W.-T. Jiang, Q.-L. Zhou, M.-Y. Xu and B. Xiao, ACS Catal., 2018, 8, 9287-9291; (e) M.-Y. Xu, W.-T. Jiang, Y. Li, Q.-H. Xu, Q.-L. Zhou, S. Yang and B. Xiao, J. Am. Chem. Soc., 2019, 141, 7582-7588; (f) W.-T. Jiang, M.-Y. Xu, S. Yang, X.-Y. Xie and B. Xiao, Angew. Chem. Int. Ed., 2020, 59, 20450-20454; (g) C. Fricke, A. Dahiya, W. B. Reid and F. Shoenebeck, ACS Catal., 2019, 9, 9231-9236; (h) C. Fricke, G. J. Sherborne, I. Funes-Ardoiz, E. Senol, S. Guven and F. Schoenebeck, Angew. Chem. Int. Ed., 2019, 58, 17788-17795; (i) G. J. Sherborne, A. G. Gevondian, I. Funes-Ardoiz, A. Dahiya, C. Fricke and F. Schoenebeck, Angew. Chem. Int. Ed., 2020, 59, 15543-15548; (j) A. Dahiya, C. Fricke and F. Schoenebeck, J. Am. Chem. Soc., 2020, 142, 7754-7759; (k) A. Selmani, A. G. Gevondian and F. Schoenebeck, Org. Lett., 2020, 22, 4802-4805.

2 (a) J. M. Buriak, Chem. Rev., 2002, 102, 1271-1306; (b) T. A. Su, H. Li, R. S. Klausen, N. T. Kim, M. Neupane, J. L. Leighton, M. L. Steigerwald, L. Venkataraman and C. Nuckolls, Acc. Chem. Res., 2017, 50, 10881095.

3 For reviews on hydrogermylation, see: (a) W. Wolfsberger, J. Prakt. Chem., 1992, 334, 453-464; (b) A. P. Dobbs and F. K. I. Chio, Hydrometallation Group 4 (Si, Ge, Sn, and Pb). Comprehensive Organic Synthesis, 2nd ed., ed. P. Kochel, Elsevier, 2014, pp 964-998. 
For transition metal-mediated hydrogermylations, see: (a) T. Matsuda, S. Kadowaki, Y. Yamaguchi and M. Murakami, Org. Lett., 2010, 12, 1056-1058; (b) S. M. Rummelt, K. Radkowski, D.-A. Roşca and A. Fürstner, J. Am. Chem. Soc., 2015, 137, 5506-5519; (c) V. Debrauwer, A. Turlik, L. Rummler, A. Prescimone, N. Blanchard, K. N. Houk and V. Bizet, J. Am. Chem. Soc., 2020, 142, 11153-11164.

5 For radical-hydrogermylations, see: (a) K. Nozaki, Y. Ichinose, K. Wakamatsu, K. Oshima and K. Utimoto, Bull. Chem. Soc. Jpn., 1990, 63, 2268-2272; (b) S. Bernardoni, M. Lucarini, G. F. Pedulli, L. Valgimigli, V. Gevorgyan and C. Chatgilialoglu, J. Org. Chem., 1997, 62, 8009-8014; (c) H. Kinoshita, H. Kakiya and K. Oshima, Bull. Chem. Soc. Jpn., 2000, 73, 2159-2160.

6 (a) C. Eaborn, R. E. E. Hill and P. Simpson, J. Organomet. Chem., 1972, 37, 275-279; (b) W. Kitching, H. Olszowy and K. Harvey, J. Org. Chem., 1981, 46, 2423-2424.

7 W. Xue, W. Mao, L. Zhang and M. Oestreich, Angew. Chem. Int. Ed., 2019, 58, 6440-64433.

8 For recent reviews dealing with cross-coupling reactions from heteroatomic electrophiles, see: (a) K. M. Korch and D. A. Watson Chem. Rev., 2019, 119, 8192-8228; (b) S. Bähr, W. Xue and M. Oestreich, ACS Catal. 2019, 9, 16-24.

9 H. Kameo, H. Yamamoto, K. Ikeda, T. Isasa and D. Bourissou, J. Am. Chem. Soc., 2020, 142, 1403914044.

10 For stoichiometric Ge-F bond cleavage via ?-metathesis at Ir, see: H. Kameo, K. Ikeda, D. Bourissou, S. Sakaki, S. Takemoto, H. Nakazawa and H. Matsuzaka, Organometallics, 2016, 35, 713-719.

11 (a) P. Gualco, T.-P. Lin, M. Sircoglou, S. Ladeira, G. Bouhadir, L. M. Perez, A. Amgoune, L. Maron, F. P. Gabbaï and D. Bourissou, Angew. Chem. Int. Ed., 2009, 48, 9892-9895; (b) H. Kameo, T. Kawamoto, D. Bourissou, S. Sakaki and H. Nakazawa, Organometallics, 2015, 34, 1440-1448; (c) H. Kameo and H. Nakazawa, Chem. Rec., 2017, 17, 268-286.

12 Competitive experiments have also been performed between 1 and $3 . \ddagger$

13 (a) A. Amgoune and D. Bourissou Chem. Commun., 2011, 47, 859-871; (b) H. Kameo and H. Nakazawa, Chem. Asian. J., 2013, 8, 1720-1734; (c) G. Bouhadir and D. Bourissou, Chem. Soc. Rev. 2016, 45, 1065-1079; (d) F. You and F. P. Gabbaï, Trend in Chem., 2019, 1, 485-496.

14 (a) N. Kano, N. Yoshinari, Y. Shibata, M. Miyachi, T. Kawashima, M. Enomoto, A. Okazawa, N. Kojima, J.-D. Guo and S. Nagase, Organometalllics, 2012, 31, 8059-8062; (b) F. Hupp, M. Ma, F. Kroll, J. O. C. JimenezHalla, R. D. Dewhurst, K. Radacki, A. Stasch, C. Jones and H. Braunschweig, Chem. Eur. J., 2014, 20, 1688816898; (c) C. Gendy, A. Mansikkamäki, J. Valjus, J. Heidebrecht, P. C.-Y. Hui, G. M. Bernard, H. M. Tuononen, R. E. Wasylishen, V. K. Michaelis and R. Roesler, Angew. Chem. Int. Ed., 2019, 58, 154-158; (d) J. A. Cabeza, P. García-Álvarez, C. J. Laglera-Gándara and E. Pérez-Carreño, Chem. Commun., 2020, 56, 14095-14097.

15 B. Cordero, V. Gómez, A. E. Platero-Prats, M. Revés, J. Echeverría, E. Cremades, F. Barragán and S. Alvarez, Dalton Trans., 2008, 37, 2832-2838.

16 H. Kameo, T. Kawamoto, S. Sakaki, D. Bourissou and H. Nakazawa, Organometallics, 2014, 33, 65576567.

17 For Lewis acid-assisted $\mathrm{F}$ abstraction from a $\mathrm{Pt} \rightarrow \mathrm{Sb}-\mathrm{F}$ complex, see: D. You, H. Yang, S. Sen and F. P. Gabbaï, J. Am. Chem. Soc., 2018, 140, 9644-9651.

18 (a) W.-C. Shih, W. Gu, M. C. MacInnis, S. D. Timpa, N. Bhuvanesh, J. Zhou and O. V. Ozerov, J. Am. Chem. Soc., 2016, 138, 2086-2089; (b) W.-C. Shih, W. Gu, M. C. MacInnis, D. E. Herbert and O. V. Ozerov, Organometallics, 2017, 36, 1718-1726. 
19 (a) I.-S.Ke, J. S. Jones and F. P. Gabbaï, Angew. Chem. Int. Ed. 2014, 53, 2633-2637; (b) J. S. Jones, C. R. Wade and F. P. Gabbaï, Angew. Chem. Int. Ed., 2014, 53, 8876-8879.

20 H. Kameo, Y. Baba, S. Sakaki, D. Bourissou, H. Nakazawa and H. Matsuzaka, Organometallics, 2017, 36, 2096-2106.

\section{Entry for the Table of Contents}

Catalytic Germa-Suzuki Coupling

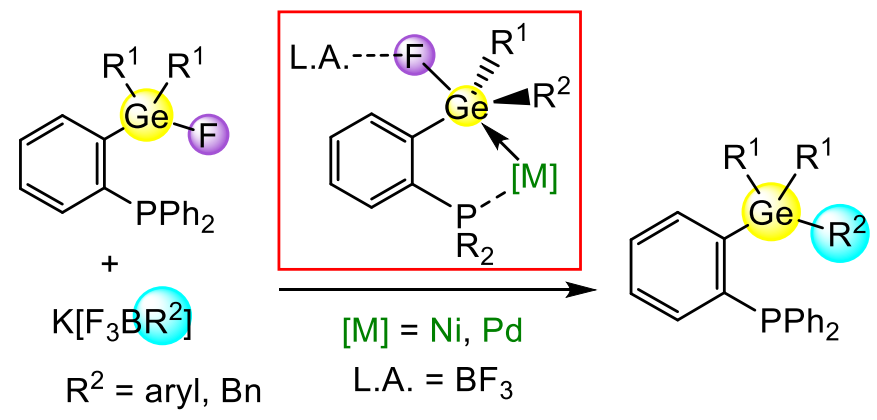

